\title{
Article \\ A Possible Preventive Role of Physically Active Lifestyle during the SARS-CoV-2 Pandemic; Might Regular Cold-Water Swimming and Exercise Reduce the Symptom Severity of COVID-19?
}

\author{
Viktor Bielik 1,*(D), Marian Grendar ${ }^{2}$ and Martin Kolisek ${ }^{2}$ \\ 1 Department of Biological and Medical Science, Faculty of Physical Education and Sport, Comenius University \\ in Bratislava, 81469 Bratislava, Slovakia \\ 2 Biomedical Center Martin, Jessenius Faculty of Medicine in Martin, Comenius University in Bratislava, \\ 03601 Martin, Slovakia; Marian.Grendar@uniba.sk (M.G.); martin.kolisek@uniba.sk (M.K.) \\ * Correspondence: viktor.bielik@uniba.sk
}

\section{check for}

updates

Citation: Bielik, V.; Grendar, M.; Kolisek, M. A Possible Preventive Role of Physically Active Lifestyle during the SARS-CoV-2 Pandemic; Might Regular Cold-Water

Swimming and Exercise Reduce the Symptom Severity of COVID-19? Int. J. Environ. Res. Public Health 2021, 18, 7158. https://doi.org/10.3390/ ijerph18137158

Academic Editor: Paul B. Tchounwou

Received: 3 May 2021

Accepted: 30 June 2021

Published: 4 July 2021

Publisher's Note: MDPI stays neutral with regard to jurisdictional claims in published maps and institutional affiliations.

Copyright: (c) 2021 by the authors. Licensee MDPI, Basel, Switzerland. This article is an open access article distributed under the terms and conditions of the Creative Commons Attribution (CC BY) license (https:// creativecommons.org/licenses/by/ $4.0 /)$.
Abstract: The objective of this study was to investigate the incidence and course of COVID-19 and the risk of an upper respiratory tract infection in a group of people with physically active lifestyles. Data were collected anonymously using an online survey platform during December 2020. The age of participants ranged from 18 to 65 years. Out of 2343 participants, 11.5\% overcame COVID-19 infection. Relative to the control group (CTRL), physically active, cold-water swimmers (PACW) did not exhibit a lower risk of incidence for COVID-19 (RR 1.074, CI 95\% (0.710-1.625). However, PACW had a higher chance of having an asymptomatic course of COVID-19 (RR 2.321, CI 95\% (0.836-6.442); $p<0.05)$ and a higher chance of only having an acute respiratory infection once or less per year than CTRL (RR 1.923, CI 95\% (1.1641-2.253); $p<0.01$ ). Furthermore, PACW exhibited a lower incidence of acute respiratory infection occurring more than twice per year (RR 0.258, CI 95\% (0.138-0.483); $p<0.01$ ). Cold-water swimming and physical activity may not lessen the risk of COVID-19 in recreational athletes. However, a physically active lifestyle might have a positive effect on the rate of incidence of acute respiratory infection and on the severity of COVID-19 symptoms.

Keywords: cold-water swimming; acute respiratory infection; athletes; physical activity; BMI

\section{Introduction}

Cold-water swimming involves whole-body immersion in cold-water outdoors (lake, river, sea, etc.) mainly during the winter season or in the colder regions. The taking of a cold-water bath together with winter or ice swimming has long been a tradition in northern countries [1]. Until a few years ago, cold-water swimming was practiced by a very close community of enthusiasts. Today, it is a popular sport and recreational activity around the world, with 50 countries having branches of the International Ice Swimming Association (IISA) [2]. Cold-water treatment is believed to contribute to regeneration after a period of intense exercise. During the procedure, a substantial part of the human body or the whole body is immersed in a bath of cold or ice-containing water for a limited duration. Evidence suggests that repeated cold-water therapy has a wide variety of health benefits [3-5] and that winter swimming has a positive impact on the immune system [1].

Similarly, a plethora of health benefits of physical activity has been documented in recent decades [6]. Indeed, a positive linear relationship seems to exist between physical activity and the health status of an individual. Thus, increased intensity of physical activity and above-average fitness lead to additional improvements in the health status of humans [7]. On the contrary, an unhealthy lifestyle, obesity, and chronic ailments jointly impair immune functions/responses and increase the risk of severe infectious disease [8]. 
Recently, Sallis et al. [9] reported that physically inactive patients were more likely to be hospitalized with COVID-19 and had a greater risk of admission to intensive care units and of mortality. However, still, a healthy lifestyle and physical fitness have been speculated to be key factors in resisting infection with SARS-CoV-2 [10,11]. These assumptions have been made based on reports correlating increased resistance to viruses such as SARS-CoV2 with modification of the risk factors for obesity and chronic diseases [8,12]. Practical recommendations and exercise advice have been published during the COVID-19 pandemic in order to address the global problem of lower physical activity and to encourage active lifestyles [13-16]. Nevertheless, whether regular cold-water swimming and/or physical activity have superior benefits for the prevention of COVID-19 and/or contribution to an asymptomatic or a less severe course of the disease needs to be better understood. Furthermore, knowledge is limited concerning the annual number of infections of the upper respiratory tract in cold-water swimmers and the physically active [17].

The purpose of this study has therefore been to identify the existence of any differences between cold-water swimmers, physically active subjects, and healthy controls with regard to the incidence of COVID-19 and upper respiratory tract infections. Furthermore, we aimed to examine whether COVID-19-infected cold-water swimmers and athletes experienced milder symptoms than a sedentary control group. Our results lead us to hypothesize that a combination of cold-water swimming and regular sport has substantial preventive benefits for reducing upper respiratory tract infections and COVID-19 severity.

\section{Materials and Methods}

\subsection{Participants}

A total of 2343 participants completed our questionnaire. Participants were recruited via flyers, print and web advertisements, social media, and websites of the Slovak Ice-Bears Organization and various athletic clubs. Moreover, students of the Faculty of Physical Education and Sport, Comenius University in Bratislava were addressed due to sport history. Students of Faculty of Electrical Engineering and Information Technology, the Slovak University of Technology in Bratislava were approached with the assumption of a sedentary lifestyle. Data were collected anonymously by using the online survey platform Survio (Brno, Czech Republic). Informed consent was provided by participants ticking a mandatory box presented prior to their proceeding to the survey. Participation was voluntary, and no financial compensation or course credit was provided in exchange for participation. The data collection began on 7 December and ended on 18 December 2020. On 11 August, the Minister of Health confirmed the second wave of the pandemic [18]. The Government of the Slovak Republic declared a state of emergency on 1 October 2020, which lasted until 14 May $2021[19,20]$. As of 12 October, teaching at all secondary schools was interrupted and was switched to distance learning. On 18 December, the Statistical Office of the Slovak Republic reported 149,275 positive COVID-19 patients from 3,718,060 Slovaks (15-65 years).

\subsection{Data Collection}

The following inclusion criteria were specified to create a group: (1) physically active, cold-water swimmers (defined as frequency of 2-3 cold-water swimming sessions/week, experience with cold-water swimming $\geq 2$ seasons, frequency of exercise $\geq 3$ active sport sessions/week), (2) physically active (frequency of exercise $\geq 3$ active sport sessions/week), and (3) control subjects ( $\leq 120 \mathrm{~min}$ physical exercise/week). An electronic questionnaire (SF1) was used to collect anonymous data. The items were piloted with a smaller representative group of cold-water swimmers $(n=404)$ to check item saliency, relevance, appropriateness, and clarity in capturing the construct of interest. All participants provided favorable responses and offered valuable feedback regarding the content and clarity of the items and instructions. Development of the questionnaire including a pilot study and the use of appropriate language resulted in a final version of the questionnaire that was understandable among the target population of recreationally active and sedentary respon- 
In the original cohort $(n=2343), 269(11.5 \%)$ participants had been tested positive for SARS-CoV-2 between the 1 March and the 30 November 2020, and of these, $97(4.1 \%)$ had been tested positive for SARS-CoV-2 by the COVID-19 antigen-test, 147 (6.3\%) by RT-PCR alone and 25 (1.1\%) by RT-PCR and the COVID-19 antigen-test (Table 2).

Table 2. Data distribution with respect to diagnostic test used for detecting COVID-19 $(n=2343)$.

\begin{tabular}{|c|c|c|c|c|}
\hline & Antigen Test & $\begin{array}{c}\text { PCR and } \\
\text { Antigen Test }\end{array}$ & PCR Test & $p$ \\
\hline gender & & & & 0.62 \\
\hline male & $48(49 \%)$ & $12(48 \%)$ & $81(55 \%)$ & \\
\hline female & $49(51 \%)$ & $13(52 \%)$ & $66(45 \%)$ & \\
\hline age (years) & $31(22,43)$ & $28(22,42)$ & $31(22,42)$ & 0.88 \\
\hline height $(\mathrm{cm})$ & $174(167,180)$ & $176(168,183)$ & $175(168,183)$ & 0.49 \\
\hline weight $(\mathrm{kg})$ & $78(63,86)$ & $73(60,86)$ & $75(62,86)$ & 0.76 \\
\hline \multicolumn{5}{|l|}{ physical activity } \\
\hline sedentary & $21(22 \%)$ & $5(20 \%)$ & $33(22 \%)$ & \\
\hline recreational athlete (3-5 h/week) & $46(47 \%)$ & $9(36 \%)$ & $60(41 \%)$ & \\
\hline recreational athlete (6-9 h/week) & $24(25 \%)$ & $8(32 \%)$ & $41(28 \%)$ & \\
\hline sub-elite athlete (>10 h/week) & $6(6.2 \%)$ & $3(12 \%)$ & $13(8.8 \%)$ & \\
\hline cold-water swimming (year) & & & & 0.76 \\
\hline none & $53(55 \%)$ & $14(56 \%)$ & $76(52 \%)$ & \\
\hline first & $22(23 \%)$ & $4(16 \%)$ & $30(20 \%)$ & \\
\hline second to third & $10(10 \%)$ & $3(12 \%)$ & $27(18 \%)$ & \\
\hline fourth to fifth & $7(7 \%)$ & $2(8.0 \%)$ & $8(5.4 \%)$ & \\
\hline sixth and more & $5(5 \%)$ & $2(8.0 \%)$ & $6(4.1 \%)$ & \\
\hline $\begin{array}{c}\text { cold-water swimming } \\
\text { (days/week) }\end{array}$ & & & & 0.65 \\
\hline none & $50(52 \%)$ & $13(52 \%)$ & $76(52 \%)$ & \\
\hline once & $13(13 \%)$ & $3(12 \%)$ & $31(21 \%)$ & \\
\hline twice & $24(25 \%)$ & $7(28 \%)$ & $27(18 \%)$ & \\
\hline three times and more & $10(10 \%)$ & $2(8 \%)$ & $13(8.8 \%)$ & \\
\hline positive for COVID-19 & & & & 0.00 \\
\hline no & $31(32 \%)$ & $7(28 \%)$ & $10(6.8 \%)$ & \\
\hline yes (from March to September) & $5(5.2 \%)$ & $2(8.0 \%)$ & $21(14 \%)$ & \\
\hline yes (from October to December) & $61(63 \%)$ & $16(64 \%)$ & $116(79 \%)$ & \\
\hline course of COVID-19 & & & & 0.06 \\
\hline asymptomatic & $22(29 \%)$ & $2(11 \%)$ & $35(25 \%)$ & \\
\hline mild & $29(39 \%)$ & $10(56 \%)$ & $40(28 \%)$ & \\
\hline moderate & $24(32 \%)$ & $5(28 \%)$ & $61(43 \%)$ & \\
\hline severe & $0(0 \%)$ & $1(5.6 \%)$ & $5(3.5 \%)$ & \\
\hline unknown & 22 & 7 & 6 & \\
\hline incidence of ARTI/yr & & & & 0.21 \\
\hline$<$ once & $55(57 \%)$ & $13(52 \%)$ & $70(48 \%)$ & \\
\hline once & $26(27 \%)$ & $4(16 \%)$ & $46(31 \%)$ & \\
\hline twice & $10(10 \%)$ & $4(16 \%)$ & $24(16 \%)$ & \\
\hline$>$ twice & $6(6.2 \%)$ & $4(16 \%)$ & $7(4.8 \%)$ & \\
\hline
\end{tabular}

Statistics presented: $n(\%)$, median (IQR) Statistical test performed: chi-square test of independence, KruskalWallis test, Fisher test; * ARTI—acute respiratory tract infection.

\subsection{Risk of Infection and Course of COVID-19}

In comparison with the control group, neither the physically active group nor the physically active, cold-water swimmers exhibited a lower risk of being positive for SARSCoV-2 (RR 0.992, 95\% CI, 0.685 to 1.439; RR 1.074, 95\% CI 0.710 to 1.625) (Table 3). The physically active, cold-water swimmers had more than a two-fold higher chance of having an asymptomatic course of COVID-19 when they tested positive for SARS-CoV-2 (RR 2.321 , CI $95 \% 0.836$ to 6.442 ). Neither the physically active group nor the physically active, cold-water swimmers exhibited a lower risk of having moderate or severe symptoms of COVID-19. 
Table 3. Risk ratios for diagnostics and course of COVID-19 and acute respiratory infection $(n=1544)$.

\begin{tabular}{|c|c|c|c|c|c|c|}
\hline & \multicolumn{2}{|l|}{ Model 1} & \multicolumn{2}{|l|}{ Model 2} & \multicolumn{2}{|l|}{ Model 3} \\
\hline & RR (95\% CI) & $p$ & RR (95\% CI) & $p$ & RR (95\% CI) & $p$ \\
\hline \multicolumn{7}{|l|}{ COVID-19 diagnostics } \\
\hline PCR/Positive & $1.091(0.688,1.730)$ & 0.36 & $1.163(0.696,1.942)$ & 0.28 & $1.093(0.802,1.488)$ & 0.29 \\
\hline PCR + Antigen/Positive & $0.992(0.685,1.439)$ & 0.48 & $1.074(0.710,1.625)$ & 0.37 & $1.025(0.794,1.323)$ & 0.43 \\
\hline \multicolumn{7}{|l|}{ Course of COVID-19 } \\
\hline asymptomatic & $1.677(0.628,4.477)$ & 0.15 & $2.321(0.836,6.442)$ & 0.05 & $1.421(0.779,2.590)$ & 0.13 \\
\hline mild & $1.207(0.627,2.320)$ & 0.29 & $0.987(0.457,2.134)$ & 0.49 & $1.194(0.766,1.859)$ & 0.22 \\
\hline moderate & $0.696(0.399,1.213)$ & 0.1 & $0.829(0.446,1.540)$ & 0.28 & $0.760(0.504,1.146)$ & 0.1 \\
\hline severe & - & & $1.364(0.229,8.110)$ & 0.37 & $1.351(0.226,8.068)$ & 0.37 \\
\hline \multicolumn{7}{|c|}{ Incidence of acute respiratory infection/yr } \\
\hline$<$ once & $1.108(0.936,1.311)$ & 0.12 & $1.923(1.1641,2.253)$ & 0.00 & $1.070(0.916,1.249)$ & 0.20 \\
\hline once & $1.154(0.971,1.370)$ & 0.05 & $0.578(0.457,0.731)$ & 0.00 & $1.232(0.823,1.844)$ & 0.16 \\
\hline twice & $0.869(0.680,1.112)$ & 0.13 & $0.394(0.270,0.574)$ & 0.00 & $0.485(0.256,0.920)$ & 0.01 \\
\hline >twice & $0.718(0.496,1.038)$ & 0.04 & $0.258(0.138,0.483)$ & 0.00 & $0.485(0.160,1.476)$ & 0.10 \\
\hline
\end{tabular}

Model 1 physically active group; Model 2 cold-water swimmers; Model 3 males only.

\subsection{Risk of Upper Respiratory Tract Infection}

In comparison with the control group, the physically active group had a slightly lower incidence of upper respiratory tract infections occurring more than twice per year (RR 0.718, CI $95 \% 0.496$ to 1.038) (Table 3). Similarly, the physically active, cold-water swimmers had less than a 0.3-fold lower incidence of having upper respiratory tract infections occurring more than twice per year (RR 0.258 , CI $95 \% 0.138$ to 0.483 ). Furthermore, the physically active, cold-water swimmers exhibited an almost two-fold higher chance of becoming infected with such an infection only once or less per year (RR 1.923, CI 95\% 1.1641 to 2.253). Risks of upper respiratory tract infection separately for males and females are presented in Table S1.

3.3. RF Machine-Learning Analysis of the Ability of Selected Variables/Predictors to Distinguish Individually or Jointly between COVID-19 Positive and Negative Individuals

Next, we utilized RF machine-learning algorithm aiming to identify variable(s) able to discriminate between subjects with positive or negative findings for the COVID-19 tests. The following variables were used as predictors: frequency of inflammation of upper respiratory tract, weight, height, age, gender, cold/ice water swimmer (yes/no), sportsman (yes/no), and frequency of cold/ice water swimming. RF ranked them by variable importance. No formal feature selection was performed. The predictors lead to AUC $=0.537$ (Figure 1); thus, leading to the conclusion that the tested variables have only minuscule power to discriminate between the two classes of subjects.

In the following, we tested whether excluding asymptomatic COVID-19 probands and those tested only with SARS-CoV2 antigen-tests may improve the performance of the RF machine-learning predictions. In this case, the predictive power was AUC $=0.599$ (Figure 2), thus only slightly better than in the previous case. 


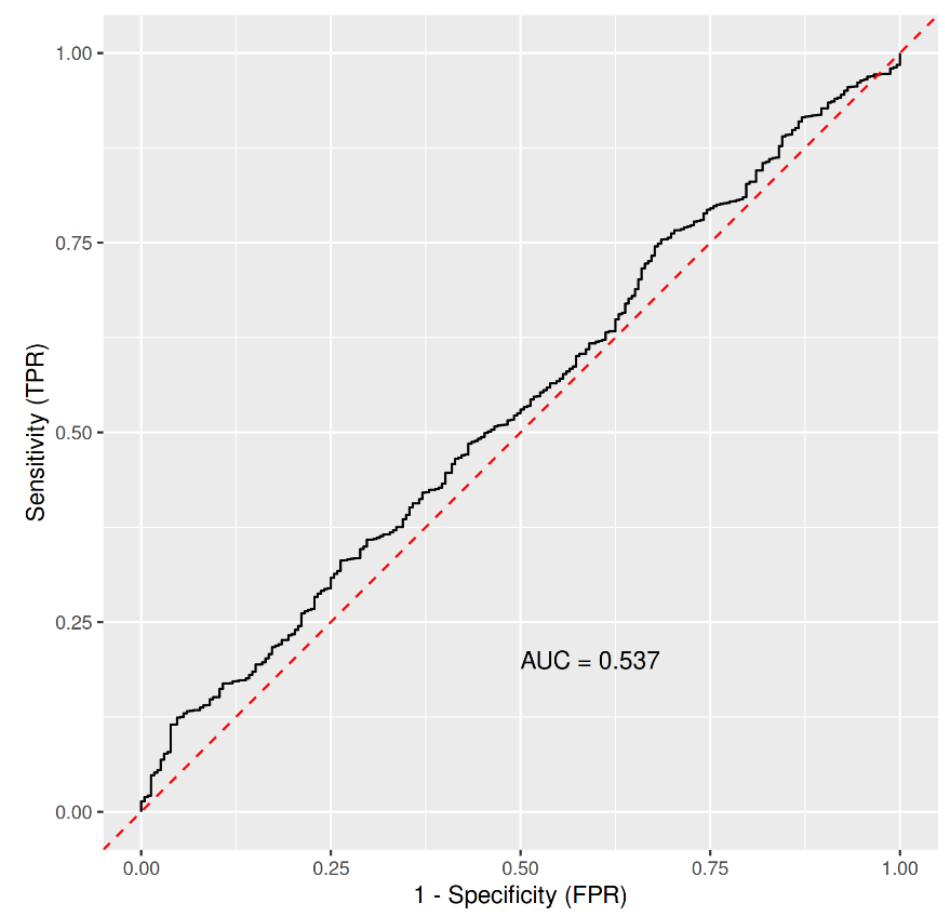

Figure 1. ROC based on the Out-Of-Bag data from imbalanced RandomForest, trained on 2111 controls (probands who were not infected with COVID-19) and 232 COVID-19 cases, with frequency of inflammation of upper respiratory tract, weight, height, age, gender, being a cold/ice water swimmer, being a sportsman, and frequency of cold/ice water swimming as predictors. Abbreviations: AUC, area under the curve; FPR, false positive rate; TPR, true positive rate.

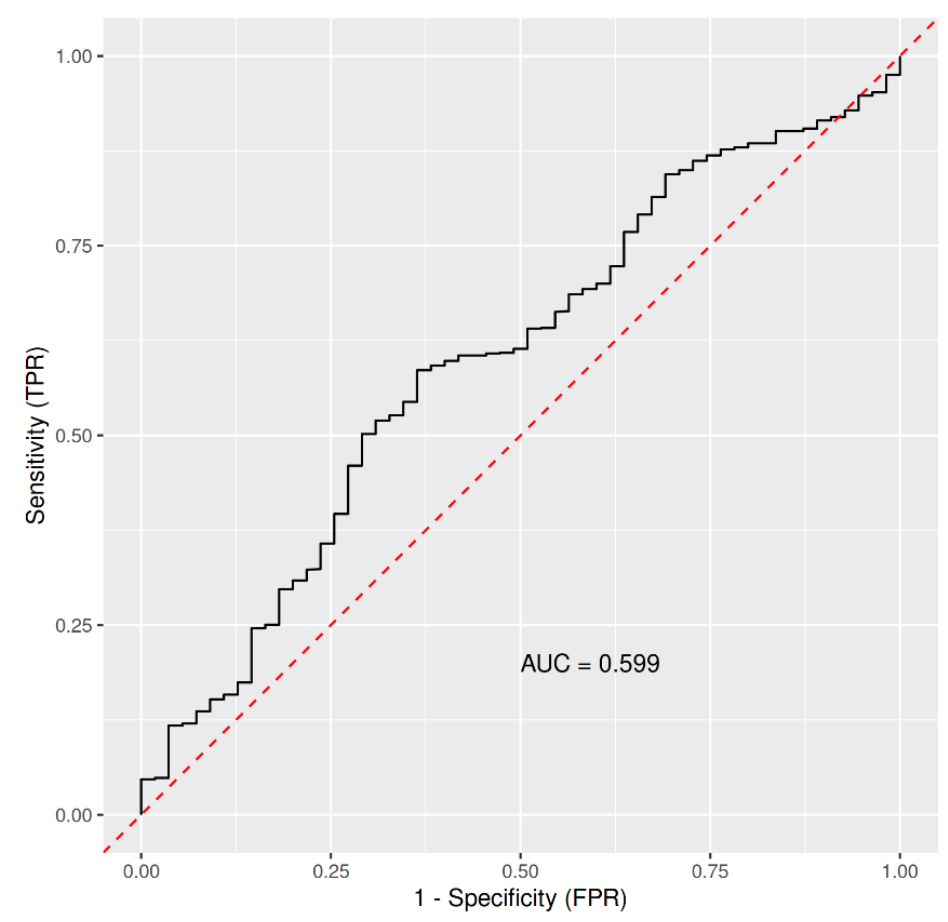

Figure 2. ROC based on the Out-Of-Bag data from imbalanced RandomForest, trained on 1130 controls (probands who were not infected with COVID-19) and 55 COVID-19 cases detected by RT-PCR, with the asymptomatic cases excluded, where frequency of inflammation of upper respiratory tract, weight, height, age, gender, being a cold-water swimmer, being a sportsman, and frequency of cold/ice water swimming were used as the predictors. Abbreviations: AUC, area under the curve; FPR, false positive rate; TPR, true positive rate. 


\section{Discussion}

We performed a cross-sectional study with the aim of identifying/deciphering any effects of a physically active lifestyle on the prevention of COVID-19 and/or acute respiratory infections. Preliminary data suggested that people with an unhealthy lifestyle and obesity were at a higher risk of suffering from the severe form of COVID-19 [12]. Obesity, accompanied by chronic inflammation and impaired immunity responses, was associated with several debilitating and life-threatening disorders. These include: respiratory dysfunction, metabolic syndrome, diabetes, cardiovascular diseases, and some malignancies. Certain metabolic risk factors are widely recognized as being related to the more severe form of COVID-19 [12]. Therefore, based on the latter, we considered the proposition that a physically active lifestyle (cold-water swimming and/or physical activity) might be advantageous in resisting infection by SARS-COV-2 [10,11]. Based on reported weekly hours of exercise, we assumed that the physically active responders have higher physical fitness than that of the control group. Brawner et al. [27] have investigated the impact of cardio-respiratory fitness (CRF), indicated by peak metabolic equivalents (METs), on hospitalization risk attributable to COVID-19. They have reported lower peak METs ( $6.7 \pm 2.8 \mathrm{METs})$ in hospitalized patients compared with those not being hospitalized $(8.0 \pm 2.4$ METs; $p<0.001)$. They conclude that CRF is independently and inversely associated with the likelihood of hospitalization because of COVID-19 [27]. This is in accordance with our study in which we report no severe COVID-19 cases with hospitalization in the group with a physically active lifestyle. However, our finding might be correlated with the nature of the cohort in our study, which consisted of relatively young individuals with low BMI. Of note, the BMI of the participants in the study of Brawner et al. (34) was on average $32.7 \mathrm{~kg} / \mathrm{m}^{2}$, which corresponds with obesity class I [28], whereas the severity of COVID-19 is generally accepted to be considerably worse in obese individuals $[29,30]$.

Surprisingly, our data showed that neither physical activity nor cold-water swimming is correlated with a lower incidence of COVID-19 when compared with the controls. Ho et al. [31] have investigated several risk factors for COVID-19. From their analysis of 235,928 eligible participants aged from 49 to 83 years, poor physical fitness (as measured by a slow walking pace), smoking, BMI, and hypertension are associated with COVID-19 [31]. On the other hand, Zbinden-Foncea [32] suggested that high levels of cardiorespiratory fitness are immuno-protective in patients who contract SARS-CoV-2. They speculate that the positive effects of moderate doses of exercise on immune protection against COVID-19 are mediated by modulation of the activity of angiotensin-converting enzyme 2 . This hypothesis has subsequently been corroborated by Motta-Santos and colleagues [33] who consider that the anti-inflammatory actions of angiotensin-(1-7) represent a positive effect of physical exercise. Notably, the physically active, cold-water swimmers in our study had a more than two-fold higher chance of having the asymptomatic form of COVID-19 when they tested positive for the disease. We speculate that they are asymptomatic because of the effect of their physically active lifestyle on their anti-inflammatory adaptation and inflammatory reactions. Recent studies suggest that physical activity mitigates some features of immunosenescence and thus improves immune responses. However, the effects of immunosenescence on the immune response against SARS-CoV-2 have been little explored [34].

One mechanism explaining the higher chance of an asymptomatic course of COVID-19 related to a physically active lifestyle might be the metabolism carried out by mitochondria, which are pivotal for the immune response [35]. Many viruses modulate the functions of mitochondria and thus affect their performance and homeostasis [36]. Therefore, differential alterations of mitochondrial functions might explain, at least to some extent, the variability in responses to SARS-CoV-2 infection among patients [10]. Nunn et al. [10] have speculated that the maintenance of "mitochondrial health" is vital for SARS-CoV-2 resistance, which is promoted by an effective mitochondrial reserve induced by factors such as physical activity. Furthermore, the key player in anti-inflammatory adaptation is mitochondrial stress, which enhances mitochondrial functions not only in muscle, but 
in various other organs in which myokines playing a key role [37]. Irisin, a thermogenic hormone-like adipomyokine possessing mitochondria-protective functions can protect against ischemia/reperfusion injury in the lung [38]. It is produced in abundance by skeletal muscle in response to exercise. Once released into the circulation, irisin acts on white adipocytes by inducing the browning response [39]. Positive effects of irisin on the expression of multiple genes related to viral infection by SARS-CoV-2 have been reported in human subcutaneous adipocytes [40]. The activity of myokines can be modulated by adipokines, confirming that crosstalk occurs between skeletal muscle and adipose tissue during metabolic regulation [41]. Exercise-induced myokines appear to be involved in mediating both systemic and local anti-inflammatory effects [42].

Mitochondrial functions and capacity can also be enhanced by brown adipose tissue, which is metabolically activated by cold exposure [43,44]. Recently, Kovaničová et al. [45] have reported that cold-acclimatized ice-water swimmers respond to cold by non-shivering thermogenesis mediated by higher fat oxidation than controls. However, it is important to note the ambient temperature (e.g., water). Swimming in mild-cold water $\left(20^{\circ} \mathrm{C}\right)$ does not activate brown adipose tissue in mice [46]. Similarly, mild cold exposure in humans does not stimulate thyroid hormone circulation [45], which has been shown to induce adipose tissue browning [47]. We assumed that the novice cold-water swimmers might have a lower adaptation to cold than experienced swimmers, and therefore, more than five hundred first-season cold-water swimmers were excluded from our final analysis. However, we do not question the positive effects of acute cooling. Indeed, the efficacy of a single exposure to cold-water immersion on recovery has been established in elite professional footballers [48]. The meta-analytical review of Poppendieck [49] has further shown that the percentage improvements of performance recovery to be expected from post-exercise cooling are large enough to be relevant for competitive athletes. Moreover, the positive effects of cooling have been demonstrated on the reduction of muscle soreness and of markers of muscle damage [49].

As described above, acute exposure to cold water temperatures is beneficial to athletic performance and recovery. However, variable degrees of body adaptation to cold only appear when such exposure is repeated regularly and long enough [50]. According to the data from our study, the physically active, cold-water swimmers had an almost two-fold higher chance of having an acute respiratory infection only once or less per year. Moreover, the physically active, cold-water swimmers exhibited less than a 0.3 -fold lower incidence of an upper respiratory tract infection occurring more than twice per year. Thus, our results are in accordance with previously published investigations, reporting that the annual number of infections of the upper respiratory tract in cold-water swimmers decreased by more than $40 \%$ when compared with those of controls [17]. Recently Kunutsor and Laukkanen [51] have evaluated the independent and joint associations of frequency of sauna bathing and cardiorespiratory fitness with pneumonia risk in 2275 men from 42 to 61 years of age. They have found that a combination of high fitness levels and frequent sauna baths is associated with a substantially lowered risk for future pneumonia compared with each modality alone. The implications of their findings with regard to altering COVID19 disease or its severity should thus be further examined [51].

A physically active lifestyle is known to boost the health of humans. Such a lifestyle might positively impact (reduce) the risk of becoming infected and adversely affected by various pathogens including SARS-CoV-2 [52]. An unhealthy lifestyle (e.g., sedentary way of life, smoking, obesity) seems to be a major risk factor for COVID-19 hospital admission. The adoption of some simple lifestyle changes might lower the risk of severe infection [11]. Unfortunately, our sample does not allow detailed analysis in this regard, but the posthoc analyses show that physically active males are at a lower rate of incidence of acute respiratory infections per year.

The main limitations of this study are that the measurements of physical activity and cold-water swimming were self-reported. Notably, because this is an observational study, we cannot clearly conclude that a physically active lifestyle with cold-water swimming is 
causally related to a higher probability of an asymptomatic COVID-19 course. Further limitations of our cohort are that weight was in the normal range, and that the individuals were relatively young. Therefore, we assume that the use of a more heterogeneous cohort would lead to more significant differences. Finally, we cannot distinguish the effect of swimming in cold water only because the ice-water swimmers reported additional physical activities. Our findings substantiate the need for an adequate physically active lifestyle and the need for governmental measures such as the meaningful support of sport/physical activities during pandemics and the massive promotion of a healthy diet. Future assessments of other risk and risk-reducing factors, such as the type, intensity, and length of physical exercise, time of cold-water swimming, and nutritional status will be necessary.

\section{Conclusions}

A physically active lifestyle, namely a combination of regular physical activity and cold-water swimming, potentially lowers the incidence of acute respiratory infection. However, cold-water swimming and physical activity might not lessen the risk of COVID19 in recreational athletes. Despite individuals with an unhealthy lifestyle and obesity being at increased risk of severe COVID-19, no evidence was presented that exercise training or cold-water swimming reduces the incidence of COVID-19. Therefore, athletes are at similar risk for COVID-19 infection as control subjects.

Supplementary Materials: The following are available online at https:/ /www.mdpi.com/article/10 .3390/ijerph18137158/s1, Table S1: Risk ratios for upper resiratory tract infection by gender.

Author Contributions: Conceptualization, V.B and M.K.; methodology, V.B. and M.K.; software, M.G.; validation, M.K. and M.G.; formal analysis, M.G.; investigation, V.B.; resources, M.G.; data curation, V.B.; writing — original draft preparation, V.B.; writing—review and editing, M.K.; visualization, M.G. and V.B.; supervision, M.K.; project administration, V.B. and M.K.; funding acquisition, M.G. and V.B. All authors have read and agreed to the published version of the manuscript.

Funding: This publication has been produced with the support of the Integrated Infrastructure Operational Program for the project: New possibilities for laboratory diagnostics and massive screening of SARS-Cov-2 and identification of mechanisms of virus behavior in human body, ITMS: 313011AUA4, co-financed by the European Regional Development Fund. Our study was also supported by funding from The Ministry of Education, Science, Research and Sport of the Slovak Republic (grant No. VEGA 1/0260/21).

Institutional Review Board Statement: Not applicable.

Informed Consent Statement: Informed consent was obtained from all subjects involved in the study. Data Availability Statement: Not applicable.

Acknowledgments: We thank all the participants. We extend our thanks also to Theresa Jones for the language editing of the manuscript.

Conflicts of Interest: The authors declare no conflict of interest.

\section{References}

1. Knechtle, B.; Waśkiewicz, Z.; Sousa, C.V.; Hill, L.; Nikolaidis, P.T. Cold Water Swimming—Benefits and Risks: A Narrative Review. Int. J. Environ. Res. Public Health 2020, 17, 8984. [CrossRef]

2. Skopich, Y. Swim Season Opens in December. The Moscow Times, 11 December 2019.

3. Zenner, R.; De Decker, D.; Clement, D. Blood-pressure response to swimming in ice-cold water. Lancet 1980, 315, 120-121. [CrossRef]

4. Checinska-Maciejewska, Z.; Miller-Kasprzak, E.; Checinska, A.; Korek, E.; Gibas-Dorna, M.; Adamczak-Ratajczak, A.; Bogdanski, P.; Krauss, H. Gender-related effect of cold water swimming on the seasonal changes in lipid profile, ApoB/ApoA-I ratio, and homocysteine concentration in cold water swimmers. J. Physiol. Pharmacol. 2017, 68, 887-896.

5. Gibas-Dorna, M.; Checinska, Z.; Korek, E.; Kupsz, J.; Sowinska, A.; Krauss, H. Cold Water Swimming Beneficially Modulates Insulin Sensitivity in Middle-Aged Individuals. J. Aging Phys. Act. 2016, 24, 547-554. [CrossRef] [PubMed]

6. Hills, A.P.; Street, S.J.; Byrne, N.M. Physical Activity and Health: “What is Old is New Again”. Adv. Food Nutr. Res. 2015, 75, 77-95. [PubMed] 
7. Warburton, D.E.; Nicol, C.W.; Bredin, S.S. Health benefits of physical activity: The evidence. Can. Med. Assoc. J. 2006, 174, 801-809. [CrossRef] [PubMed]

8. de Frel, D.L.; Atsma, D.E.; Pijl, H.; Seidell, J.C.; Leenen, P.J.M.; Dik, W.A.; van Rossum, E.F.C. The Impact of Obesity and Lifestyle on the Immune System and Susceptibility to Infections Such as COVID-19. Front. Nutr. 2020, 7, 597600. [CrossRef] [PubMed]

9. Sallis, R.; Young, D.R.; Tartof, S.Y.; Sallis, J.F.; Sall, J.; Li, Q.; Smith, G.N.; Cohen, D.A. Physical inactivity is associated with a higher risk for severe COVID-19 outcomes: A study in 48440 adult patients. Br. J. Sports Med. 2021. [CrossRef]

10. Nunn, A.V.W.; Guy, G.W.; Brysch, W.; Botchway, S.W.; Frasch, W.; Calabrese, E.J.; Bell, J.D. SARS-CoV-2 and mitochondrial health: Implications of lifestyle and ageing. Immun. Ageing 2020, 17, 33. [CrossRef] [PubMed]

11. Hamer, M.; Kivimäki, M.; Gale, C.R.; Batty, G.D. Lifestyle risk factors, inflammatory mechanisms, and COVID-19 hospitalization: A community-based cohort study of 387,109 adults in UK. Brain Behav. Immun. 2020, 87, 184-187. [CrossRef]

12. Stefan, N.; Birkenfeld, A.L.; Schulze, M.B.; Ludwig, D. Obesity and impaired metabolic health in patients with COVID-19. Nat. Rev. Endocrinol. 2020, 16, 341-342. [CrossRef]

13. Nyenhuis, S.M.; Greiwe, J.; Zeiger, J.S.; Nanda, A.; Cooke, A. Exercise and Fitness in the Age of Social Distancing During the COVID-19 Pandemic. J. Allergy Clin. Immunol. Pract. 2020, 8, 2152-2155. [CrossRef]

14. Gentil, P.; De Lira, C.A.B.; Souza, D.; Jimenez, A.; Mayo, X.; Gryschek, A.L.D.F.P.L.; Pereira, E.; Alcaraz, P.; Bianco, A.; Paoli, A.; et al. Resistance Training Safety during and after the SARS-Cov-2 Outbreak: Practical Recommendations. BioMed Res. Int. 2020, 2020, 1-7. [CrossRef] [PubMed]

15. Dwyer, M.J.; Pasini, M.; De Dominicis, S.; Righi, E. Physical activity: Benefits and challenges during the COVID-19 pandemic. Scand. J. Med. Sci. Sports 2020, 30, 1291-1294. [CrossRef]

16. Bentlage, E.; Ammar, A.; How, D.; Ahmed, M.; Trabelsi, K.; Chtourou, H.; Brach, M. Practical Recommendations for Maintaining Active Lifestyle during the COVID-19 Pandemic: A Systematic Literature Review. Int. J. Environ. Res. Public Health 2020, 17, 6265. [CrossRef] [PubMed]

17. Siems, W.G.; Brenke, R.; Sommerburg, O.; Grune, T. Improved antioxidative protection in winter swimmers. QJM 1999, 92, 193-198. [CrossRef] [PubMed]

18. Ministry of Health of the Slovak Republic. Available online: https:/ /www.health.gov.sk/Clanok?covid-19-komisia-pandemickaplan (accessed on 15 June 2021).

19. Ministry of Interior of the Slovak Republic. Available online: https:/ /www.minv.sk/?tlacove-spravy-4\&sprava=koronavirusmame-cestovny-semafor (accessed on 15 June 2021).

20. Ministry of Interior of the Slovak Republic. Available online: https:/ / www.minv.sk/?tlacove-spravy\&sprava=od-1-oktobraplati-na-slovensku-nudzovy-stav (accessed on 15 June 2021).

21. Craig, C.L.; Marshall, A.L.; Sjöström, M.; Bauman, A.E.; Booth, M.L.; Ainsworth, B.E.; Pratt, M.; Ekelund, U.; Yngve, A.; Sallis, J.F.; et al. International physical activity questionnaire: 12-country reliability and validity. Med. Sci. Sports Exerc. 2003, 35, $1381-1395$. [CrossRef]

22. Thomaz, P.M.D.; da Silva, E.F.; da Costa, T.H.M. Validity of self-reported height, weight and body mass index in the adult population of Brasilia, Brazil. Rev. Bras. Epidemiol. 2013, 16, 157-169. [CrossRef]

23. R Core Team. R: A Language and Environment for Statistical Computing. R Foundation for Statistical Computing: Vienna, Austria, 2020. Available online: http:/ / www.r-project.org/index.html (accessed on 14 April 2021).

24. Eklund, A. Beeswarm: The Bee Swarm Plot, an Alternative to Stripchart. Available online: https: / / cran.r-project.org/package= beeswarm (accessed on 14 April 2021).

25. Fast Unified Random Forests for Survival, Regression, and Classification (RF-SRC). Available online: https://cran.r-project.org/ web / packages/randomForestSRC/randomForestSRC.pdf (accessed on 16 March 2021).

26. Ehrlinger, J. ggRandomForests: Visually Exploring Random Forests. Available online: https:// cran.r-project.org/package= ggRandomForests (accessed on 14 April 2021).

27. Brawner, C.A.; Ehrman, J.K.; Bole, S.; Kerrigan, D.J.; Parikh, S.S.; Lewis, B.K.; Gindi, R.M.; Keteyian, C.; Abdul-Nour, K.; Keteyian, S.J. Inverse Relationship of Maximal Exercise Capacity to Hospitalization Secondary to Coronavirus Disease 2019. Mayo Clin. Proc. 2021, 96, 32-39. [CrossRef]

28. Weir, C.B.; Jan, A. BMI Classification Percentile and Cut off Points. In StatPearls; StatPearls Publishing: Treasure Island, FL, USA, 2021.

29. Sharma, A.; Garg, A.; Rout, A.; Lavie, C.J. Association of Obesity With More Critical Illness in COVID-19. Mayo Clin. Proc. 2020, 95, 2040-2042. [CrossRef]

30. Sanchis-Gomar, F.; Lavie, C.J.; Mehra, M.R.; Henry, B.M.; Lippi, G. Obesity and Outcomes in COVID-19: When an Epidemic and Pandemic Collide. Mayo Clin. Proc. 2020, 95, 1445-1453. [CrossRef] [PubMed]

31. Ho, F.K.; Celis-Morales, C.A.; Gray, S.R.; Katikireddi, S.V.; Niedzwiedz, C.L.; Hastie, C.; Ferguson, L.D.; Berry, C.; Mackay, D.F.; Gill, J.M.; et al. Modifiable and non-modifiable risk factors for COVID-19, and comparison to risk factors for influenza and pneumonia: Results from a UK Biobank prospective cohort study. BMJ Open 2020, 10, e040402. Available online: https: // pubmed.ncbi.nlm.nih.gov/33444201 (accessed on 12 January 2021). [CrossRef] [PubMed]

32. Zbinden-Foncea, H.; Francaux, M.; Deldicque, L.; Hawley, J.A. Does High Cardiorespiratory Fitness Confer Some Protection Against Proinflammatory Responses After Infection by SARS-CoV-2? Obesity 2020, 28, 1378-1381. [CrossRef] [PubMed] 
33. Motta-Santos, D.; Santos, R.A.S.; Santos, S.H.S. Angiotensin-(1-7) and Obesity: Role in Cardiorespiratory Fitness and COVID-19 Implications. Obesity 2020, 28, 1786. [CrossRef] [PubMed]

34. Filgueira, T.O.; Castoldi, A.; Santos, L.E.R.; de Amorim, G.J.; de Sousa Fernandes, M.S.; De Lima Do Nascimento Anastácio, W.; Campos, E.Z.; Santos, T.M.; Souto, F.O. The Relevance of a Physical Active Lifestyle and Physical Fitness on Immune Defense: Mitigating Disease Burden, with Focus on COVID-19 Consequences. Front. Immunol. 2021, 12, 587146. [CrossRef]

35. Monlun, M.; Hyernard, C.; Blanco, P.; Lartigue, L.; Faustin, B. Mitochondria as Molecular Platforms Integrating Multiple Innate Immune Signalings. J. Mol. Biol. 2017, 429, 1-13. [CrossRef]

36. Khan, M.; Syed, G.H.; Kim, S.-J.; Siddiqui, A. Mitochondrial dynamics and viral infections: A close nexus. Biochim. Biophys. Acta Mol. Cell Res. 2015, 1853 Pt B, 2822-2833. Available online: https://www.sciencedirect.com/science/article/pii/S0167488915000 099 (accessed on 12 January 2021).

37. Laurens, C.; Bergouignan, A.; Moro, C. Exercise-Released Myokines in the Control of Energy Metabolism. Front. Physiol. 2020, 11, 91. [CrossRef]

38. Chen, K.; Xu, Z.; Liu, Y.; Wang, Z.; Li, Y.; Xu, X.; Chen, C.; Xia, T.; Liao, Q.; Yao, Y.; et al. Irisin protects mitochondria function during pulmonary ischemia/reperfusion injury. Sci. Transl. Med. 2017, 9, eaao6298. [CrossRef]

39. Colaianni, G.; Cinti, S.; Colucci, S.; Grano, M. Irisin and musculoskeletal health. Ann. N. Y. Acad. Sci. 2017, 1402, 5-9. [CrossRef] [PubMed]

40. de Oliveira, M.; De Sibio, M.T.; Mathias, L.S.; Rodrigues, B.M.; Sakalem, M.E.; Nogueira, C.R. Irisin modulates genes associated with severe coronavirus disease (COVID-19) outcome in human subcutaneous adipocytes cell culture. Mol. Cell. Endocrinol. 2020, 515, 110917. [CrossRef] [PubMed]

41. Rodríguez, A.; Becerril, S.; Ezquerro, S.; Méndez-Giménez, L.; Frühbeck, G. Crosstalk between adipokines and myokines in fat browning. Acta Physiol. 2017, 219, 362-381. [CrossRef] [PubMed]

42. Brandt, C.; Pedersen, B.K. The role of exercise-induced myokines in muscle homeostasis and the defense against chronic diseases. J. Biomed. Biotechnol. 2010, 2010, 520258. [CrossRef] [PubMed]

43. McNeill, B.T.; Morton, N.M.; Stimson, R.H. Substrate Utilization by Brown Adipose Tissue: What's Hot and What's Not? Front. Endocrinol. 2020, 11, 571659. [CrossRef]

44. Liepinsh, E.; Makarova, E.; Plakane, L.; Konrade, I.; Liepins, K.; Videja, M.; Sevostjanovs, E.; Grinberga, S.; Makrecka-Kuka, M.; Dambrova, M. Low-intensity exercise stimulates bioenergetics and increases fat oxidation in mitochondria of blood mononuclear cells from sedentary adults. Physiol. Rep. 2020, 8, e14489. [CrossRef] [PubMed]

45. Kovaničová, Z.; Kurdiová, T.; Baláž, M.; Štefanička, P.; Varga, L.; Kulterer, O.C.; Betz, M.J.; Haug, A.R.; Burger, I.A.; Kiefer, F.W.; et al. Cold Exposure Distinctively Modulates Parathyroid and Thyroid Hormones in Cold-Acclimatized and Non-Acclimatized Humans. Endocrinology 2020, 161. [CrossRef]

46. da Silva, J.T.; Cella, P.S.; Testa, M.T.; de Jesus Testa, M.T.; Perandini, L.A.; Festuccia, W.T.; Deminice, R.; Chimin, P. Mild-cold water swimming does not exacerbate white adipose tissue browning and brown adipose tissue activation in mice. J. Physiol. Biochem. 2020, 76, 663-672. [CrossRef]

47. Junker, D.; Syväri, J.; Weidlich, D.; Holzapfel, C.; Drabsch, T.; Waschulzik, B.; Rummeny, E.J.; Hauner, H.; Karampinos, D.C. Investigation of the Relationship between MR-Based Supraclavicular Fat Fraction and Thyroid Hormones. Obes. Facts 2020, 13, 331-343. [CrossRef]

48. Elias, G.P.; Wyckelsma, V.; Varley, M.; McKenna, M.; Aughey, R. Effectiveness of Water Immersion on Postmatch Recovery in Elite Professional Footballers. Int. J. Sports Physiol. Perform. 2013, 8, 243-253. [CrossRef]

49. Poppendieck, W.; Faude, O.; Wegmann, M.; Meyer, T. Cooling and Performance Recovery of Trained Athletes: A Meta-Analytical Review. Int. J. Sports Physiol. Perform. 2013, 8, 227-242. [CrossRef]

50. Manolis, A.S.; Manolis, S.A.; Manolis, A.A.; Manolis, T.A.; Apostolaki, N.; Melita, H. Winter Swimming: Body Hardening and Cardiorespiratory Protection Via Sustainable Acclimation. Curr. Sports Med. Rep. 2019, 18, 401-415. [CrossRef]

51. Kunutsor, S.K.; Laukkanen, J.A. High fitness levels, frequent sauna bathing and risk of pneumonia in a cohort study: Are there potential implications for COVID-19? Eur. J. Clin. Investig. 2021, 51, e13490. [CrossRef] [PubMed]

52. Wang, M.; Baker, J.S.; Quan, W.; Shen, S.; Fekete, G.; Gu, Y. A Preventive Role of Exercise Across the Coronavirus 2 (SARS-CoV-2) Pandemic. Front. Physiol. 2020, 11, 572718. [CrossRef] [PubMed] 